\title{
Produksi Bio-Oil dari Rumput Gajah dengan Fast Pyrolysis menggunakan Circulating Fluidized Bed Reactor (CFBr) dengan Kapasitas 45 Kg/H
}

\author{
Ilham Mufandi a,1,*, W. Treedet ${ }^{\mathrm{a}, 2}$, P. Singbua ${ }^{\mathrm{a}, 3}$, R. Suntivarakon ${ }^{\mathrm{a}, 4}$ \\ ${ }^{a}$ Department of Mechanical Engineering, Faculty of Engineering, Khon Kaen University, 123 Moo 16, Mitrapap Rd, Nai-Muang, Muang District, Khon \\ Kaen 40002. \\ ${ }^{1}$ Ilhammufandi1805@gmail.com \\ * corresponding author
}

\section{ARTICLE INFO}

Article history

Received February 02, 2019

Revised March 22, 2019

Accepted March 22, 2019

Keywords

Bio-oil production

Circulating Fluidized Bed (CFBr)

Fast Pyrolysis

\begin{abstract}
The objective of this work was to produce the renewable liquid fuel (Bio-oil) form Napier grass by fast pyrolysis in a circulating fluidized bed reactor. The experiment was conducted to improve the bio-oil production (pyrolysis oil) using the condenser. Circulating fluidized bed reactor had a height of $4.5 \mathrm{~m}$, sand as bed material with a diameter 249 $\mathrm{nm}$ and Napier grass as the raw material for bio-oil production. The parameter in this work compared with previous research. The experiment was carried out at different temperature ranging from 440 ${ }^{\circ} \mathrm{C}, 460{ }^{\circ} \mathrm{C}, 480{ }^{\circ} \mathrm{C}, 500{ }^{\circ} \mathrm{C}$ and $520{ }^{\circ} \mathrm{C}$; feed rate biomass at $45 \mathrm{~kg} / \mathrm{h}$ and a superficial velocity $7 \mathrm{~m} / \mathrm{s}$. The experimental result shown that the maximum yield was $39.60 \%$ at pyrolysis temperature of $480{ }^{\circ} \mathrm{C}$ as the best temperature. While the bio-char production and Non condensable gas (NCG) was at $10.67 \%$ and $49.73 \%$. Respectively, these results indicated that the condenser can be improve the bio-oil production yield in the system. Furthermore, the condenser process has been shown to have a direct effect on the bio-oil yield.
\end{abstract}

This is an open access article under the CC-BY-SA license.

\section{Pendahuluan}

Kebutuhan energi mengalami peningkatan yang sangat pesat karena pertumbuhan populasi. Indonesia merupakan negara dengan konsumsi energi terbesar di kawasan Asia Tenggara dan urutan kelima di kawasan Asia Pasifik dalam konsumsi energi primer setelah Cina, India, Jepang dan Korea Selatan [1]. Selain itu juga Indonesia menjadi negara Net Importir BBM sejak 2014. Energi fosil menjadi primadona di Indonesia, disisi lain energi fosil mengakibatkan kerusakan lingkungan, efek rumah kaca, pemanasan global dan lainnya.

Sumber energi terbarukan seperti biomassa menjadi perhatian khusus untuk mengatasi permasalahan energi di Indonesia. Biomassa merupakan limbah padatan seperti limbah pertanian, produk kehutanan dan limbah kota dapat digunakan untuk produksi energi dengan cara gasifikasi dan pirolisis [2]. Biomasa dapat dirubah menjadi 3 tipe energi yaitu energi listrik, bahan bakar transportasi dan bahan baku kimia [3].

Pengembangan energi biomassa di indonesia menjadi perhatian khusus untuk menyelamatkan energi masa depan. Indonesia mempunyai cadangan biomassa yang melimpah, hal ini menjadi keuntungan bagi Indonesia untuk mengurangi gas emisi dan meningkatkan pasokan energi. Berdasarkan Konferensi Tingkat Tinggi Perubahan Iklim Dunia (UNFCCC COP21) yang diselenggarakan tahun 2015 di Paris bahwa Indonesia berkomitmen untuk menurunkan emisi gas rumah kaca (GRK) pata tahun 2020 sebesar 26\% dengan upaya sendiri. 
Energi dari biomassa ditemukan dengan cara thermochemical process seperti gasifikasi, pirolisis dan pembakaran. Banyak penelitian yang sudah melakukan pengembangan di energi terbarukan biomassa seperti yang dilakukan oleh W. Treedet and R. Suntivarakorn [4] melakukan penelitian bio-oil production dengan menggunakan proses pirolisis. Penelitian dari S. Bunchan, et.al. [5] melakukan pengembangan energi terbarukan biomass dengan proses gasifikasi. Namun, pengembangan energi terbarukan biomass masing menjadi trend bagi para peneliti untuk menemukan produk bio-oil yang optimal. Tujuan pada penelitian ini adalah (1) untuk mengamati pengaruh suhu pirolisis pada produk bio-oil dari Napier grass. (2) menemukan suhu maksimal pada fast pirolisis dari napier grass.

\section{Metodologi Penelitian}

\subsection{Bahan Penelitian}

Sampel biomassa didapat dari Napier grass (Pennisetum Purpureum) di Khon Kaen, Thailand. Bahan penunjang dalam penelitian yang digunakan adalah pasir dan LPG (Liquid Petroleum Gas). Pasir digunakan sebagai pembawa panas untuk mentrasnfer panas dengan cepat dari LPG ke Napier grass sedangkan LPG digunakan sebagai gas pembawa Napier grass untuk sirkulasi di CFBr. Napier grass tumbuh secara cepat dengan interval 3 bulan kemudian digiling menggunakan mesin giling dengan ukuran 1-3 mm sebelum digunakan dalam penelitian. Sifat fisik Napier grass seperti bulk density, mean diameter, porosity, dan heating value dapat dilihat di Tabel 1. Yang mana heating value dari napier grass berdasarkan ASTM D240. Analisis proximate dari Napier grass seperti Moisture, Volatile matter, fixed carbon, dan ash dapat dilihat di Tabel 2. Analisa unsur pada Napier grass seperti $\mathrm{C}, \mathrm{H}, \mathrm{N}, \mathrm{S}$, and $\mathrm{O}$ dapat dilihat di Tabel 3. Yang mana analisa unsur ditampilkan menggunakan Perkin Elmer PE2400 series II.

Tabel 1. Sifat fisik pada Napier grass.

\begin{tabular}{lccc}
\hline Komponen & Napier grass & Sand & Satuan \\
\hline Mean diameter & $1-2$ & 0.249 & $\mathrm{~mm}$ \\
\hline Bulk density & 137.8 & 1524 & $\mathrm{Kg} / \mathrm{m}^{2}$ \\
\hline Porosity & - & 42.87 & $\%$ \\
\hline Heating value (ASTJ D240) & 15.23 & - & $\mathrm{MJ} / \mathrm{Kg}$ \\
\hline
\end{tabular}

Tabel 2. Analisa Proximate pada Napier grass

\begin{tabular}{lccc}
\hline Komponen & Napier grass & Sand & Satuan \\
\hline Moisture & 12.14 & - & $w t \%$ \\
\hline Volatile matter $^{\mathrm{a}} \%$ & 75.37 & - & $w t \%$ \\
\hline${\text { Fixed } \text { carbon }^{\mathrm{a}}}_{\text {Ash }}$ & 7.33 & - & $w t \%$ \\
\hline
\end{tabular}

Tabel 3. Sifat unsur pada Napier grass

\begin{tabular}{cccc}
\hline Komponen & Napier grass & Sand & Satuan \\
\hline $\mathrm{C}$ & 40.03 & - & $\%$ \\
\hline $\mathrm{H}$ & 6.02 & - & $\%$ \\
\hline $\mathrm{S}$ & 1.69 & - & $\%$ \\
\hline $\mathrm{O}^{\mathrm{a}}$ & 1.08 & - & $\%$ \\
\hline
\end{tabular}

${ }^{\mathrm{a}}$ Fixed carbon and oxygen

were calculated by difference 


\subsection{Alat Penelitian}

Alat penelitian terdiri dari Circulating Fluidized Bed reactor $(\mathrm{CFBr})$, gas combustion, dua screw feeders, sebuah hopper, dua cyclones, gas pre-heater, dua kondenser, thermocouples dan empat pressures meter. Alat penelitian dapat dilihat pada Gambar 1. Screw feeders memiliki beberapa konfigurasi dan ukuran; pertama digunakan untuk mengontrol bahan baku dan kedua digunakan untuk mengoperasikan kecepatan yang tinggi dan menjaga bahan baku agar tidak terbang. Hopper digunakan untuk tempat bahan baku. CFBr memiliki tinggi $4,5 \mathrm{~m}$ dan diameter $10 \mathrm{~cm}$ yang mana Napier grass dibakar secara cepat dalam system fast pyrolysis menggunakan LPG sebagai gas medium untuk membakar Napier grass. Cyclones digunakan untuk memisahkan partikel padatan seperti biochar and ash. Dua condenser digunakan untuk merubah fase dari gas yang panas ke liquid. Dalam sistem penelitian ini ada dua operasi dari condenser yaitu condenser yang pertama dioperasikan pada temperatur sampai $60{ }^{\circ} \mathrm{C}$ sedangkan condenser kedua dioperasikan pada temperatur sampai $25^{\circ} \mathrm{C} .4$ unit thermocouple digunakan untuk monitor dan kontrol proses pirolisis.

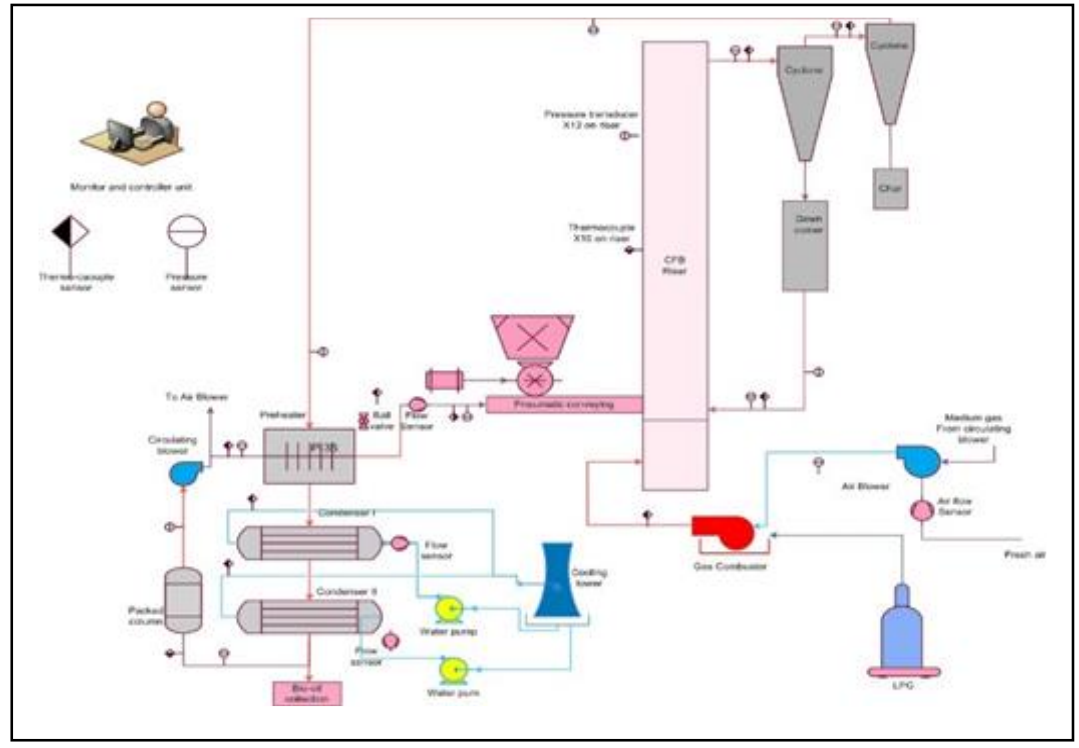

Gambar 1. Diagram proses fast pyrolysis

\subsection{Alat Penelitian}

Pertama, proses Fast Pyrolysis menggunakan bahan baku Napier grass. Kecepatan yang digunakan adalah $7 \mathrm{~m} / \mathrm{s}$ yang mana temperatur bed diatur dengan variasi suhu sebagai berikut 440 ${ }^{\circ} \mathrm{C}, 460{ }^{\circ} \mathrm{C}, 480{ }^{\circ} \mathrm{C}, 500{ }^{\circ} \mathrm{C}$ dan $520{ }^{\circ} \mathrm{C}$. Penentuan suhu operasi berdasarkan jenis pirolisis yang digunakan. Pada penelitian ini menggunakan jenis fast pyrolysis yaitu proses pembakaran biomassa dengan laju cepat dari range suhu $450-600{ }^{\circ} \mathrm{C}$ dalam kondisi tanpa udara. Hasil dari proses Fast Pyrolysis ditampung pada tempat penyimpanan di unit kondenser. Proses pendinginan memiliki kecepatan yang tinggi untuk merubah fase dari gas ke cair sehingga sangat efektif untuk mengurangi Non-Condensable Gas (NCG) [6]. Dalam persentase produk pirolisis terdiri dari 3 produk yaitu liquid, padatan, dan gas jika dijumlahkan dari 3 produk tersebut harus sama dengan $100 \%$.

\section{Hasil dan Pembahasan}

\subsection{Pengaruh temperatur pada bio-oil production}

Pada gambar 2. hasil pirolisis dari Napier grass dengan kapasitas $45 \mathrm{~kg} / \mathrm{h}$. masing-masing, dari penelitian ini dapat ditampilkan bahwa proses Fast Pyrolysis menghasilkan maximum yield sekitar $39,60 \%$ pada temperatur $480{ }^{\circ} \mathrm{C}$ dan kecepatan $7 \mathrm{~m} / \mathrm{s}$. Temperatur memiliki pengaruh pada produk bio-oil yang mana untuk alasan ini dapat dijelaskan bahwa suhu di bawah $440^{\circ} \mathrm{C}$ menghasilkan biooil dengan jumlah yang rendah tetapi menhasilkan charcoal yang tinggi. Sedangkan suhu di atas $520^{\circ} \mathrm{C}$ sangat tinggi untuk memproduksi bio-oil sehingga produk bio-oil akan menurun secara cepat.

Pada penelitian ini ditemukan bahwa (1) pada suhu $440-520{ }^{\circ} \mathrm{C}$, minyak hasil pirolisis meningkat dan kemudian mengalami penurunan. (2) Non-Condensable Gas (NCG) dan hasil charcoal mengalami perubahan grafik yang tidak teratur hal ini dipengaruhi oleh suhu pembakaran 
di reaktor. Pembakaran biomassa (Napier grass) di dalam riser memerlukan suhu yang stabil agar hasil yang diperoleh maksimal. Berdasarkan beberapa penelitian bahwa perubahan suhu dalam reaktor mempengaruhi hasil dari oil, charcoal and NCG. Hubungan antara produk pirolisis dan suhu ditampilkan pada Gambar 2. Pada penelitian ini ditemukan 3 produk seperti charcoal, liquid fuel dan Non condensable gas.

Pengaruh suhu pada hasil pirolisis dalam penelitian ini memiliki hasil yang serupa dengan pengaruh suhu pirolisis yang diteliti oleh W. Treedet and R. Suntivarakorn [7] dan P. Singbua, et.al. [8] tetapi pada penelitian kami bahwa menghasilkan produk yang lebih banyak dari produk yang diteliti oleh P. Singbua, et.al. [8] dan R. Yin, et.al. [9] dapat dilihat pada gambar 3. Karena pada penelitian ini untuk meningkatkan produk yang dihasilkan dari proses pirolisis dengan cara menambahkan kondenser unit dengan suhu operasi pendinginan sampai $25{ }^{\circ} \mathrm{C}$ yang mana fungsi dari penambahan kondenser ini untukk meningkatkan efisiensi pada perubahan bentuk gas menjadi liquid. secara dasar produksi bio-oil dihasilkan dari perubahan fase dari gas ke liquid yang terjadi di kondenser.

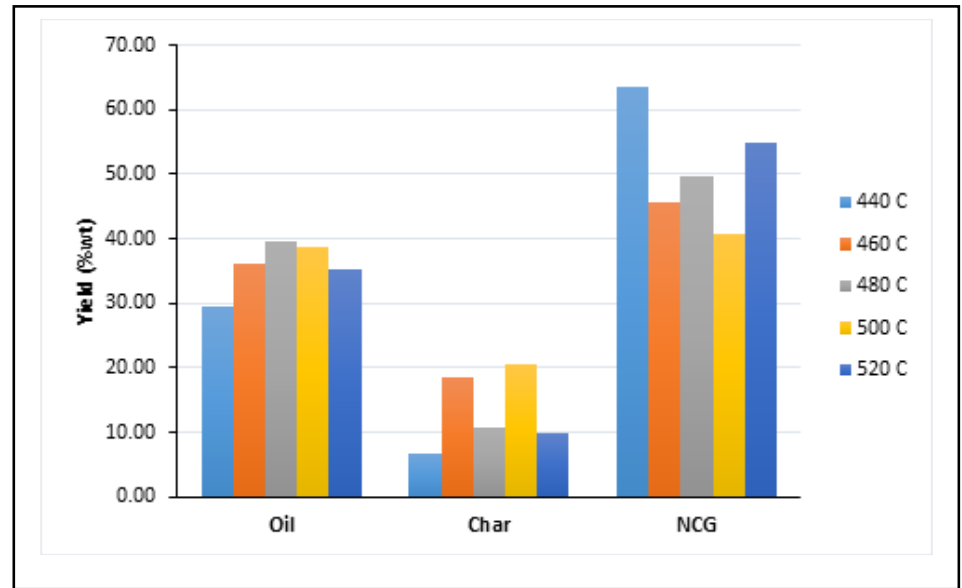

Gambar 2. Pengaruh suhu pada bio-oil production

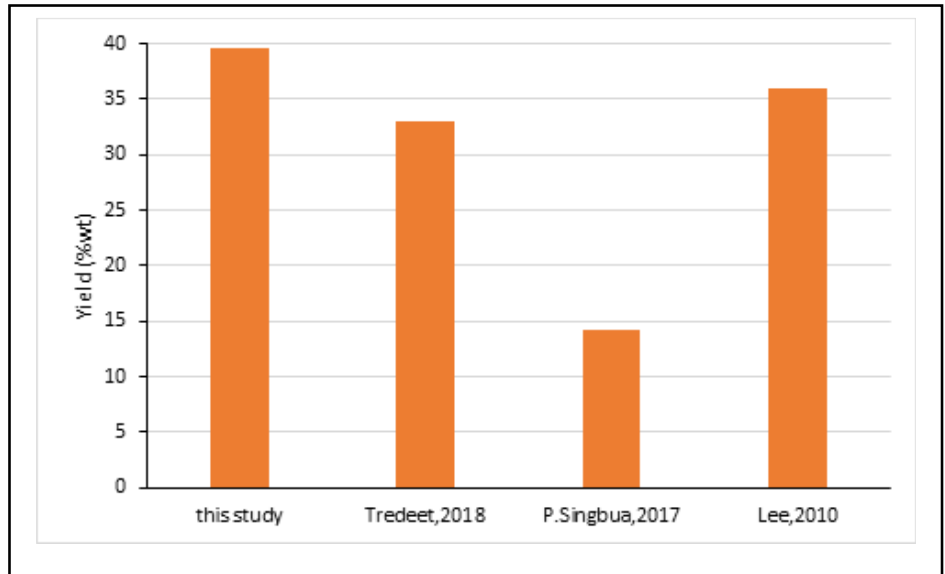

Gambar 3. Perbandingan Bio-oil production dengan peneliti sebelumnya

\section{Kesimpulan}

Proses pirolisis yang digunakan adalah jenis fast pirolisis yang mana jenis pirolisis sendiri memiliki 2 jenis yaitu slow pyrolysis dan fast pyrolysis. Pada penelitian ini, proses fast pirolisis dari napier grass dilakukan dengan sebuah reaktor circulating fluidized bed. Hasil pirolisis dipengaruhi oleh suhu. Suhu operasi dari $440-520{ }^{\circ} \mathrm{C}$ menunjukan bahwa hasil pirolisis mengalami kenaikan dan kemudian mengalami penuruan sesuai dengan suhu operasi. Proses pirolisis dari napier grass menjadi bio-oil mempunyai suhu optimum. Hasil dari penelitian fast pirolisis dari Napier grass yaitu maximum yield dan suhu optimum pada feed rate napier grass $45 \mathrm{~kg} / \mathrm{h}$. Hasil maksimal fast pirolisis adalah $39,60 \%$ dan suhu optimal pada $480{ }^{\circ} \mathrm{C}$. hasil penelitian jika dibandingkan dengan penelitian 
sebelumnya [10] tetapi pada hasil bio-oil dari penelitan kami memiliki hasil yang lebih banyak dari pada penelitian dari P. Singbua, et.al. [8]. Karena pada penelitian ini untuk meningkatkan produk yang dihasilkan dari pirolisis proses dilakukan dengan menambah unit kondeser dengan operasi suhu sampai $25{ }^{\circ} \mathrm{C}$ yang mana fungsi dari penambahan condenser ini untuk meningkatkan efisiensi pada perubahan bentuk gas menjadi liquid. Secara dasar produksi bio-oil dihasilkan dari perubahan fase dari gas ke liquid yang terjadi di condenser.

\section{Ucapan Terimakasih}

Penelitian ini menerima dana hibah dari Faculty of Engineering Khon Kaen University, Thailand. Selanjutnya, Penulis mengucapkan terima kasih kepada Farm Engineering and Automation Technology (FEAT) Research Group, Khon Kaen University, Thailand atas dukungan finansial dan teknis.

\section{Daftar Pustaka}

[1] E. O. 2018 Indonesia, Energi berkelanjutan untuk transportasi darat. 2018.

[2] A. V. Bridgwater, D. Meier, and D. Radlein, "An overview of fast pyrolysis of biomass," Org. Geochem., vol. 30, no. 12, pp. 1479-1493, 1999.

[3] P. McKendry, "Energy production from biomass (part 1): overview of biomass," Bioresour. Technol, vol. 83, no. 1, pp. 37-46, 2002.

[4] W. Treedet and R. Suntivarakorn, "Sugar Cane Trash Pyrolysis for Bio-oil Production in a Fluidized Bed Reactor," pp. 140-147, 2011.

[5] S. Bunchan, T. Poowadin, and K. Trairatanasirichai, "A Study of Throat Size Effect on Downdraft Biomass Gasifier Efficiency,” Energy Procedia, vol. 138, pp. 745-750, 2017.

[6] R. Yin, R. Liu, Y. Mei, W. Fei, and X. Sun, "Characterization of bio-oil and bio-char obtained from sweet sorghum bagasse fast pyrolysis with fractional condensers," Fuel, vol. 112, pp. 96-104, 2013.

[7] W. Treedet and R. Suntivarakorn, "Design and operation of a low cost bio-oil fast pyrolysis from sugarcane bagasse on circulating fluidized bed reactor in a pilot plant," Fuel Process. Technol., vol. 179, pp. 17-31, Oct. 2018.

[8] P. Singbua, W. Treedet, P. Duangthong, V. Seithtanabutara, and R. Suntivarakorn, "Bio-Oil Production of Napier Grass by Using Rotating Cylindrical Reactor,” Energy Procedia, vol. 138, pp. 641-645, 2017.

[9] R. Yin, R. Liu, J. Wu, X. Wu, C. Sun, and C. Wu, "Influence of particle size on performance of a pilotscale fixed-bed gasification system," Bioresour. Technol., vol. 119, pp. 15-21, 2012.

[10] R. Suntivarakorn, W. Treedet, P. Singbua, and N. Teeramaetawat, "Fast pyrolysis from Napier grass for pyrolysis oil production by using circulating Fluidized Bed Reactor: Improvement of pyrolysis system and production cost," Energy Reports, vol. 4, pp. 565-575, 2018. 